\title{
Cytogenetic and Molecular Analysis of the Acute Monocytic Leukemia Cell Line THP-I With an MLL-AF9 Translocation
}

\author{
Maria D. Odero,' Nancy J. Zeleznik-Le, ${ }^{2}$ Vandana Chinwalla, ${ }^{3}$ and Janet D. Rowley ${ }^{3 *}$ \\ 'University of Navarra, Pamplona, Navarra, Spain \\ ${ }^{2}$ Loyola University Medical Center, Cardinal Bernardin Cancer Center, Maywood, Illinois \\ ${ }^{3}$ University of Chicago Medical Center, Chicago, Illinois
}

Cell lines derived from patients with leukemia are used in many molecular biology studies. Here we report the cytogenetic analysis of the THP-I cell line using G-banding, fluorescence in situ hybridization (FISH), and spectral karyotyping (SKY), and the molecular characterization of the MLL-AF9 rearrangement by RT-PCR. The THP-I cell line was established from the peripheral blood of a I-year-old boy with acute monocytic leukemia (AML-M5). THP-I is near-diploid and consists of two related subclones with a number of aberrations, including the $t(9 ; \mathrm{II})$, associated with AML M5. The use of FISH allowed us to identify and characterize otherwise hidden cytogenetic rearrangements, which include duplication of the $3^{\prime}$ portion of MLL in the derivative 9 chromosome and a deletion of the $5^{\prime}$ portion of the AF9 gene involved in the translocation. In addition to confirming the FISH results, SKY allowed for a more precise characterization of the karyotype of THP-I and allowed us to identify other abnormalities in this cell line, including $\operatorname{der}(I) t(I ; I 2), \operatorname{der}(20) t(I ; 20)$, deletions 6p, I2p, and I7p, trisomy 8, and monosomy 10. Sequencing of the RT-PCR product showed a direct in-frame fusion product on the derivative chromosome II between exon 6 (exon 9) of MLL and exon 5 of AF9, which is most commonly involved in MLL-AF9 translocations. This study demonstrates that combining different techniques to achieve a more precise characterization of the THP-I cell line provides important information that will be valuable for understanding the critical events required for leukemogenesis.

(C) 2000 Wiley-Liss, Inc.

\section{INTRODUCTION}

The $\mathrm{t}(9 ; 11)(\mathrm{p} 22 ; \mathrm{q} 23)$ is a recurring abnormality in acute myeloid leukemia (AML), usually M4 and M5. The translocation results in the fusion of MLL at 11q23 and the AF9 gene at 9p22 (Iida et al., 1993; Nakamura et al., 1993). Molecular cloning indicates that the breakpoint junctions in this translocation may be complex, with duplications or deletions of up to several hundred base pairs occurring at the junctions (Nakamura et al., 1993; Super et al., 1997).

With few exceptions, hematologic malignancies with a rearranged $M L L$ gene exhibit biological characteristics that make them poorly responsive to conventional therapies. For AML, it appears that the prognostic effect may depend on the particular MLL translocation partner involved (DiMartino and Cleary, 1999). The prognosis for children and adults with AML and $t(9 ; 11)$ is better than for patients with other abnormalities of $11 \mathrm{q} 23$, especially with intensive treatment during remission (Martinez-Clement, et al., 1995; Mrozek et al., 1997; Grimwade et al., 1998; Swansbury et al., 1998). In the $\mathrm{t}(9 ; 11)$ group, the presence of trisomy 8 was associated with a more favorable outcome, perhaps because of an inverse relationship with the presence of central nervous system disease (Swansbury et al., 1998).

The THP-1 cell line carrying a $t(9 ; 11)$ was established from the peripheral blood of a 1-yearold boy with acute monocytic leukemia (AMLM5) (Tsuchiya et al., 1980). This cell line is known to have a $\mathrm{t}(9 ; 11)$ (Drexler et al., 1995), but has not been molecularly characterized or studied in detail using newer cytogenetic techniques.

To characterize the chromosomal abnormalities more fully, we studied the THP-1 cell line using three different techniques: G-banding, fluorescence in situ hybridization (FISH), and spectral karyotyping (SKY). In order to determine whether a potentially productive MLL-AF9 fusion was formed, we performed a molecular analysis to detect this rearrangement.

*Correspondence to: Janet D. Rowley, Section of Hematology/ Oncology, University of Chicago Medical Center, 5841 S. Maryland Avenue, MC 2115, Chicago, IL 60637.

E-mail: jrowley@medicine.bsd.uchicago.edu

Received 28 February 2000; Accepted 29 June 2000 


\section{AF9 cosmid contig map}

centromere

telomere

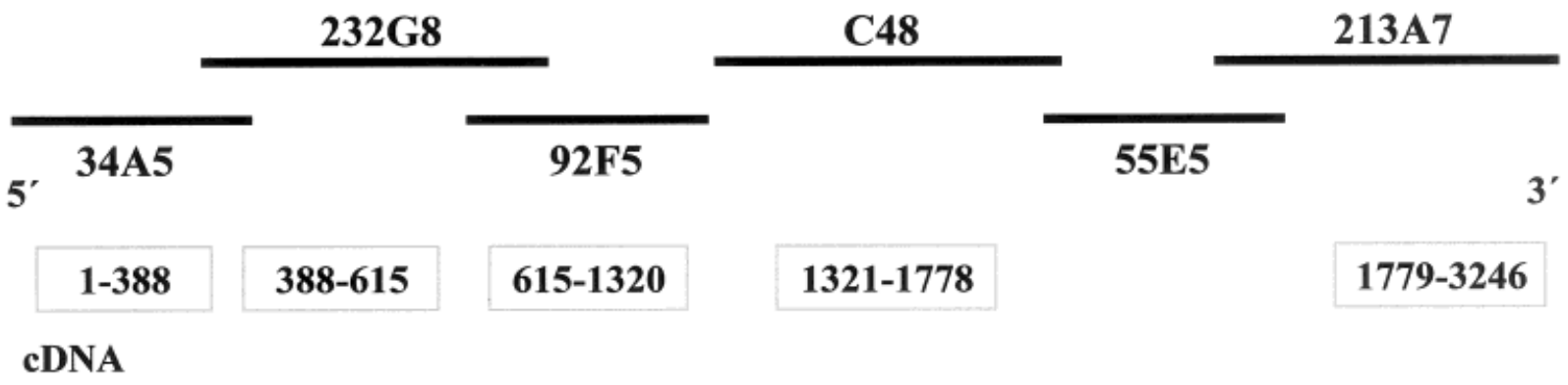

Figure I. Schematic diagram of the cDNA of the AF9 gene showing the location of the cosmid probes used for FISH relative to the cDNA sequence. The breakpoint in AF9 is in C48.

\section{MATERIALS AND METHODS}

\section{FISH Probes}

$M L L$ was analyzed using an $M L L$ probe (Oncor, Gaithersburg, MD) and an LSI MLL dual-color probe (Vysis, Downers Grove, IL). The latter probe consists of a $350-\mathrm{kb}$ portion centromeric of the MLL gene breakpoint cluster region (BCR) labeled in Spectrum Green and a 190-kb portion largely telomeric of the BCR labeled in Spectrum Orange. A cosmid contig that contained AF9 was used to analyze this gene (Strissel et al., 2000). The order of these probes is $5^{\prime}$ (centromeric) 34A5232G8-92F5-C48-55E5-213A7 (telomeric) 3' (Fig. 1). Additional FISH experiments were performed using centromere-specific probes (CEP) for chromosomes 9 and 12 (Vysis).

\section{FISH}

G-banding and FISH analysis were performed as previously described (Rowley et al., 1990). The karyotype was described according to ISCN (1995). The probes were labeled with biotin-11-dUTP or digoxigenin-11-dUTP (Boehringer Mannheim Biochemicals, Indianapolis, IN) using nick translation. The biotin-labeled probes were detected with FITC-conjugated avidin. The digoxigenin-labeled probes were detected with rhodamine-conjugated sheep antidigoxigenin antibodies (Boehringer Mannheim Biochemicals). Chromosomes were identified using counterstaining with 4'6-diamidino-2-phenylindole dihydrochloride (DAPI).

Images of the hybridized cells were captured with a liquid-cooled, charge-coupled device camera (Photometrics, Tucson, AZ). Separate gray-scale images for the DAPI and the fluorescein isothio- cyanate fluorescence were acquired. The images were merged using Adobe Photoshop (Adobe Systems, San Jose, CA) on a Macintosh computer (Apple Computers, Cupertino, CA).

\section{SKY}

The SKY probe mixture and hybridization reagents were obtained from Applied Spectral Imaging (Carlsbad, CA). Slides for spectral karyotyping were hybridized with the probe cocktail as previously described (Rowley et al., 1999) for 2 days at $37^{\circ} \mathrm{C}$. Ten metaphase cells were captured and analyzed using the SD200 system (Applied Spectral Imaging).

\section{RT-PCR}

Total RNA was extracted using TriReagent (Molecular Research Center, Cincinnati, OH). First-strand cDNA was generated with the cDNA Cycle kit (Invitrogen) and was used as template for PCR with primers EX-5-1 (MLLBCRT1) (5'GGATCCTGCCCCAAAGAAAAGCAGTAGTGAGCC-3') and AF9-AS4 (5'-CAGGATGTTCCAGATGTTTCCACT $-3^{\prime}$ ) in the first round, and EX-5-2 (Sma 1300'T) (5'-GCCAGCACTGGTCATCCCGCCTCAG-3') and AF9-AS3 (5'TTCACGATCTGCTGCAGAATGTGTCT-3') in the second round (Super et al., 1997). The RTPCR products were cloned into the pCR 2.1 vector using the TA cloning kit (Invitrogen) and were sequenced using an ABI 377 sequencer with dRhodamine terminator sequencing kit (Perkin Elmer, Warrington, U.K.). 

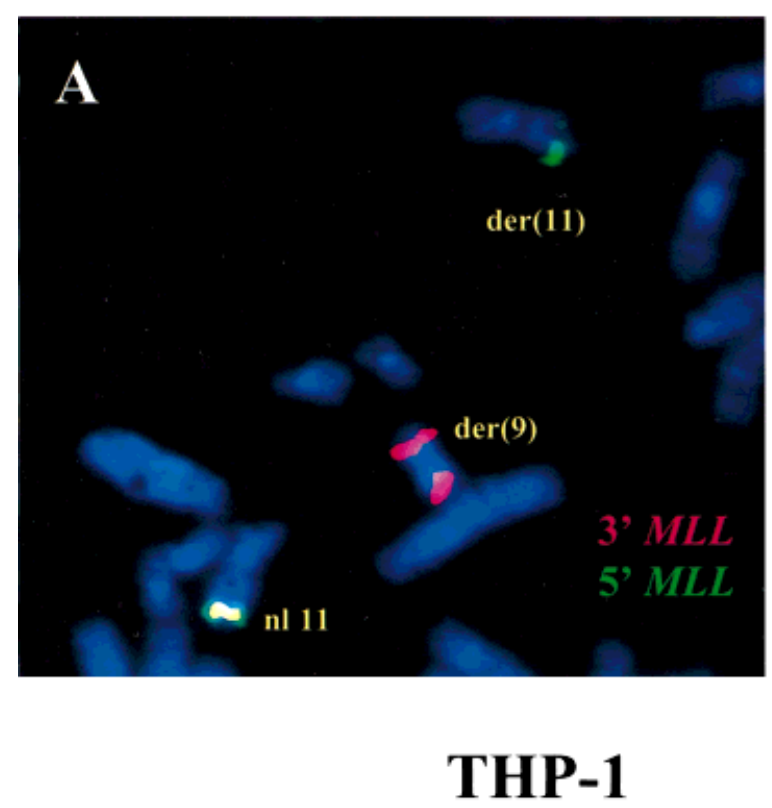

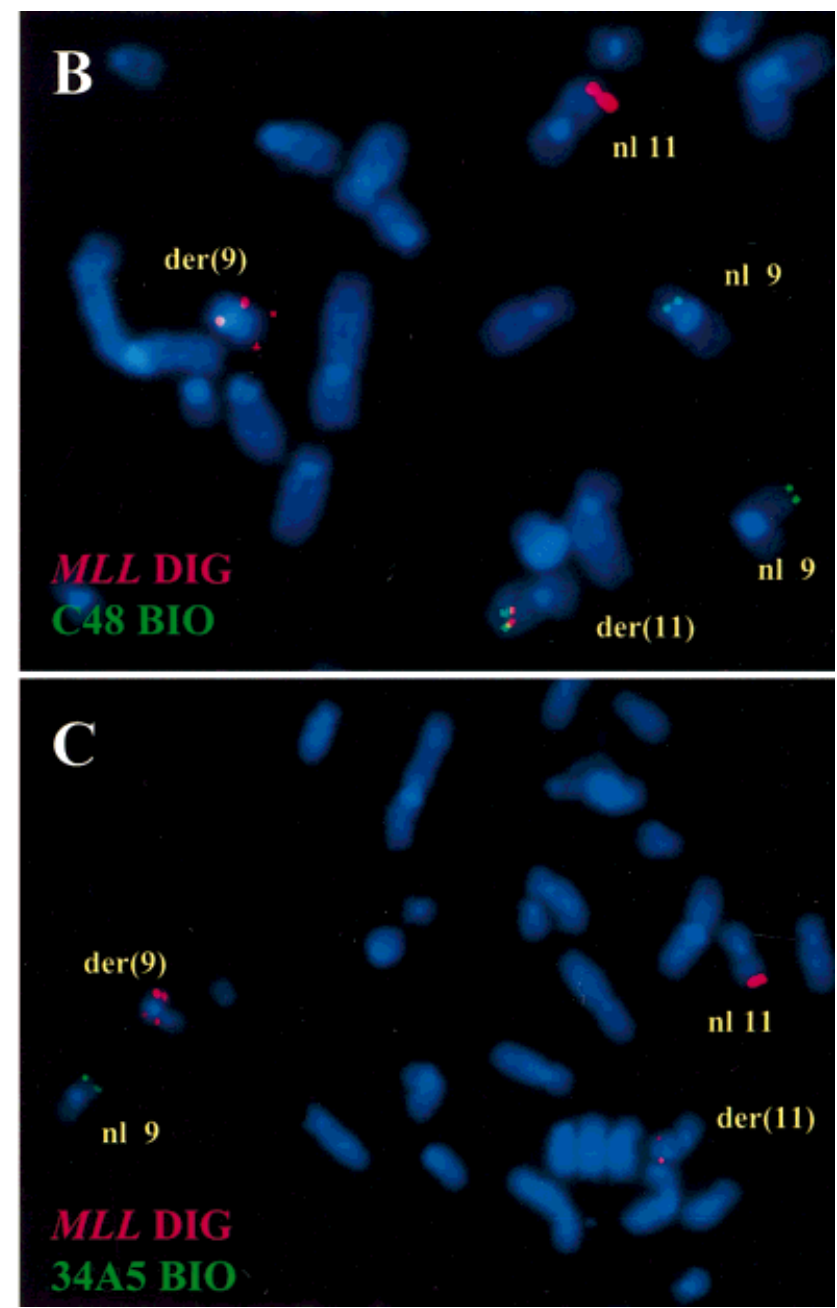

C48 was found in both normal chromosomes 9 and in the $\operatorname{der}(\mathrm{II})$. C: Labeling with the Oncor MLL probe is as in B. The AF9 cosmid 34A5 (green) was detected only in the normal chromosome 9. This broken metaphase cell contains only one chromosome 9.
Figure 2. FISH analysis of the MLL-AF9 rearrangement. A: LSI MLL
ual-color probe showing the $3^{\prime} M L L$ duplication on the $\operatorname{der}(9)$ (red); $5^{\prime}$ (II) chromosome (green). The normal II has a yellow fusion signal. B: Oncor MLL probe (red) and cosmid C48 (AF9) (green). The MLL probe labels the normal II and the $\operatorname{der}(\mathrm{II})$. Cosmid

\section{RESULTS AND DISCUSSION}

Cytogenetic analysis after performing the different techniques showed two related near-diploid clones: 49,XY,+der(1)del(1)(p22p36)t(1;12)(p36; q11), $\operatorname{del}(6)(\mathrm{p} 21),+\operatorname{del}(6)(\mathrm{p} 21),+8,+\operatorname{der}(9) \mathrm{t}(9 ;$ 11)(p22;q23)t(9;11)(q12;q23), - 10, der(11)t(9; 11)(p22; q23), del(12)(q11), del(17)(p11), der(20)ins $(20 ; 1)(\mathrm{p} 12 ; \mathrm{p} 22 \mathrm{p} 36)[13] / 48$, idem, $-\operatorname{del}(12)(\mathrm{q} 11)[7]$.

Using the LSI MLL dual color probe (Vysis), we detected a 3' MLL duplication in the der(9) chromosome. 5' MLL remained on the $\operatorname{der}(11)$ chromosome (Fig. 2A). The $\operatorname{der}(9)$ is a short chromosome with the 9p22 band fused to the 3 ' portion of the MLL gene. Unexpectedly, there is a deletion in band $9 q 12$, which is fused to another copy of $3^{\prime}$ MLL. These results were confirmed with the Oncor
MLL probe (Fig. 2B and C). The centromere probe CEP 9 confirmed that this chromosome was a der(9).

FISH analysis with the AF9 contig cosmids showed the presence of cosmids 34A5, 232G8, and 92F5 only in the normal chromosomes 9. Cosmids C48 and 55E5 were found in both normal chromosomes 9 and in the der(11) (Fig. 2B). Cosmid 34A5 was present only on the normal chromosome 9 (Fig. 2C). Thus, the MLL-AF9 fusion on the der(11) chromosome was confirmed using FISH, and the changes affecting $A F 9$ were shown to be very complex with deletion of $A F 9$ from the $\operatorname{der}(9)$ chromosome. Analysis of 10 cells with SKY confirmed the FISH results and allowed for a more complete characterization of the karyotype of the cell line (Fig. 3). 

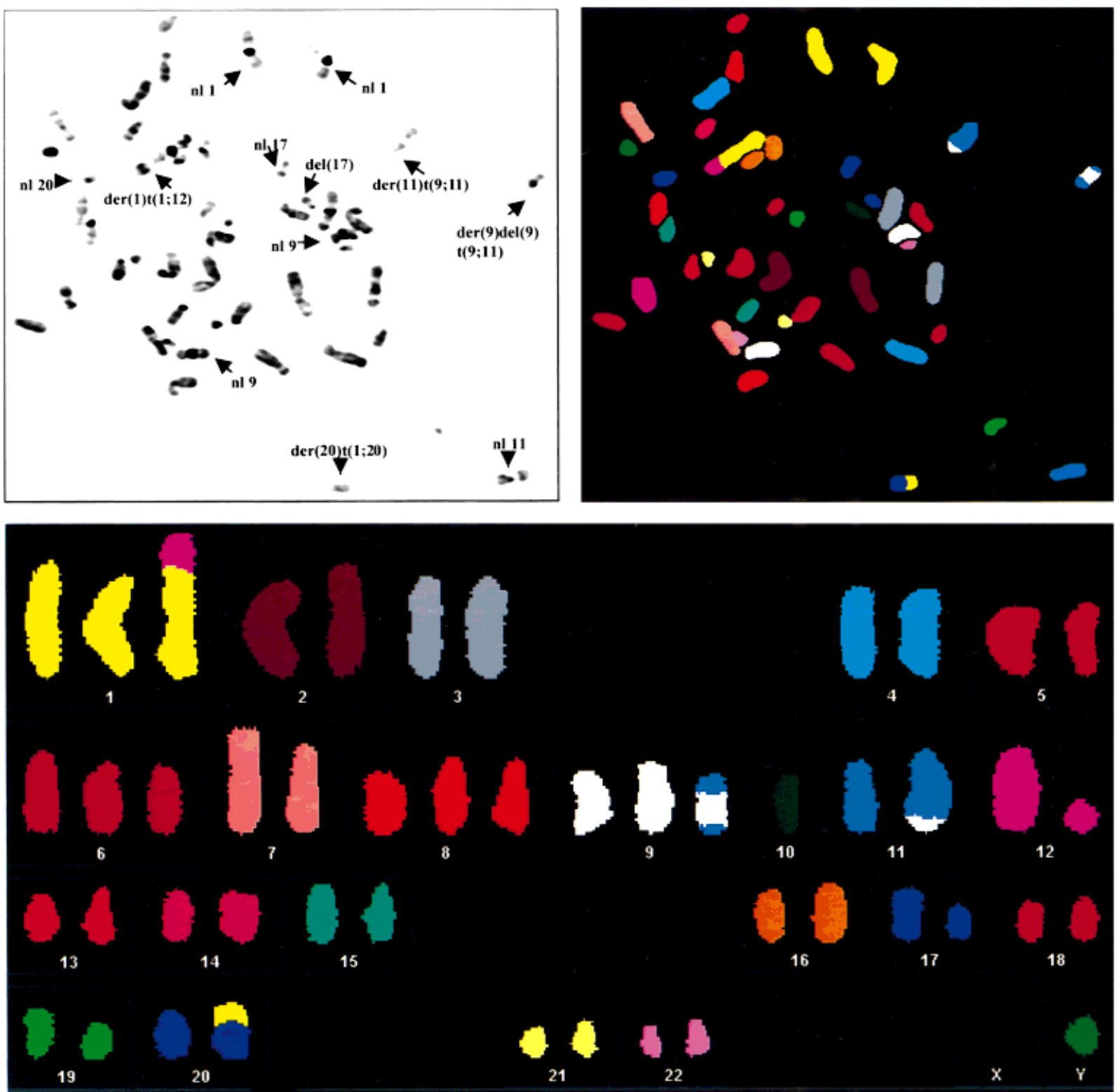

Figure 3. Spectral karyotype of THP-I. DAPI stained metaphase cell from the THP-I cell line (upper left) and classified spectral image of the same cell (upper right). Bottom: Spectral karyotype of same cell. See text for karyotype.

We analyzed the THP-1 cell line using nested RT-PCR to determine whether an $M L L-A F 9 \mathrm{fu}-$ sion was formed. Two amplification products of approximately $500 \mathrm{bp}$ and $400 \mathrm{bp}$ were observed in the second round when the MLL exon 5 (exon 8) and the $A F 9$ primers were used. MLL exons were numbered initially by $\mathrm{Gu}$ et al. (1992). Lochner et al. (1996) identified three additional exons so the new numbers are indicated in parenthesis. The amplification products were cloned and sequenced. Sequencing showed that the larger fragment was a direct in-frame fusion between exon 6 (exon 9) of
MLL and exon 5 of AF9 (Strissel et al., 2000) previously referred to as site A by Yamamoto et al. (1994). The smaller fragment showed fusion of $M L L$ exon 5 (exon 8) to the same $A F 9$ exon 5 , which would not be translated into a fusion protein because the fusion resulted in an in-frame stop codon 2 bp after the end of $M L L$ exon 5 (Fig. 4). This AF9 exon is located in cosmid C48; the majority of AFO breakpoints occur in intron 4 as is shown for this cell line (Strissel et al., 2000).

Thus, a more complete characterization of the THP-1 cell line was achieved by using all four 
$M L L$ exon 5 - $A F 9$ exon 5

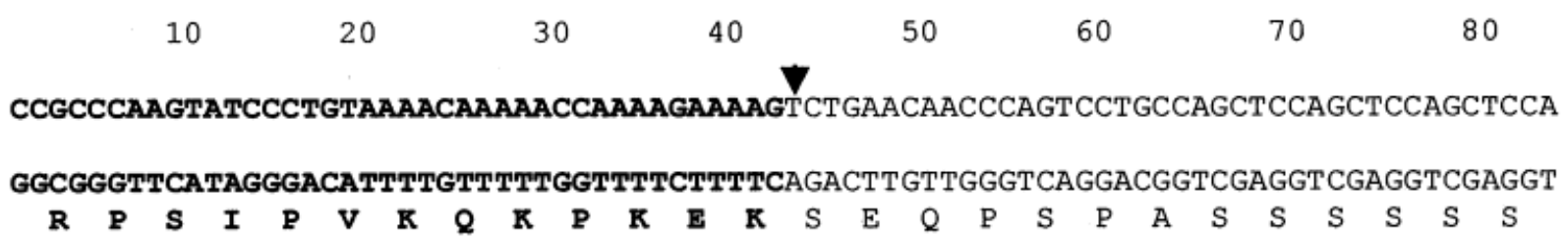

\title{
$M L L$ exon 6 - $A F 9$ exon 5
}

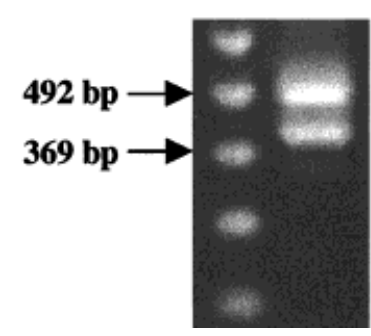

\begin{abstract}
Figure 4. Amino acid and mRNA sequences of the MLL-AF9 breakpoints in THP-I. MLL sequences are in bold type, AF9 in regular type. Arrows indicate the breakpoints. Insert: RT-PCR showing two different size fusions; MLL exon 5-AF9 exon 5 is the larger (492 bp) and MLL exon 6-AF9 exon 5 is the smaller (369 bp).
\end{abstract}

techniques in combination. Several new pieces of information were obtained. Although complex MLL-AF9 rearrangements with duplications and deletions have been described (Nakamura et al., 1993; Super et al., 1997), the 3' MLL duplication and the fusion of $9 \mathrm{q} 12$ to $3^{\prime} M L L$ have not been reported previously. It will be important to determine whether the other $3^{\prime} M L L$ fusion results in a product potentially capable of being expressed and of having an effect on the transformation process.

Swansbury et al. (1998) reported that it may be possible to identify further subgroups of $t(9 ; 11)$ patients with a relatively better or worse prognosis based on karyotypic changes. Our results show that SKY provides a useful tool to characterize the karyotype more completely. We were able to identify several other chromosomal abnormalities in addition to the $\mathrm{t}(9 ; 11)$, including $\operatorname{der}(1) \mathrm{t}(1 ; 12)$, $\operatorname{der}(20) \mathrm{t}(1 ; 20)$, deletions $6 \mathrm{p}, 12 \mathrm{p}$, and $17 \mathrm{p}$, trisomy 8 , and monosomy 10.

Using an MLL-AF9 knock in mouse, Dobson et al. (1999) reported that secondary mutations are necessary for malignancy associated with this gene fusion. Knowledge of the secondary changes in this cell line could be useful in order to study these changes at molecular level.

\section{ACKNOWLEDGMENTS}

We acknowledge the expert technical assistance of Rafael Espinosa. Supported by the Departamento de Salud, Gobierno de Navarra (Spain) (to M.D.O.) and grants from the National Cancer Institute (CA 42557) and the Spastic Paralysis Foundation of the Illinois Eastern Iowa Division of Kiwanis International (to J.D.R.).

\section{REFERENCES}

DiMartino JF, Cleary ML. 1999. MLL rearrangements in haematological malignancies: lessons from clinical and biological studies. Br J Haematol 106:614-626.

Dobson CL, Warren AJ, Pannell R, Forster A, Lavenir I, Corral J, Smith AJ, Rabbitts TH. 1999. The mll-AF9 gene fusion in mice controls myeloproliferation and specifies acute myeloid leukaemogenesis. EMBO J 18:3564-3574.

Drexler HG, MacLeod RA, Borkhardt A, Janssen JW. 1995. Recurrent chromosomal translocations and fusion genes in leukemialymphoma cell lines. Leukemia 9:480-500.

Grimwade D, Walker H, Oliver F, Wheatley K, Harrison C, Harrison G, Rees J, Hann, Stevens R, Burnett A, Goldstone A, The Medical Research Council Adult and Children's Leukaemia Working 
Parties. 1998. The importance of diagnostic cytogenetics on outcome in AML: analysis of 1,612 patients entered into the MRC AML 10 trial. Blood 92:2322-2333.

Gu Y, Nakamura T, Alder H, Prasad R, Canaani O, Cimino G, Croce C, Canaani E. 1992. The $\mathrm{t}(4 ; 11)$ chromosome translocation of human acute leukemias fuses the $A L L-1$ gene, related to Drosophilia trithorax, to the $A F-4$ gene. Cell 71:701-708.

Iida S, Seto M, Yamamoto K, Komatsu H, Tojo A, Asano S, Kamada N, Ariyoshi Y, Takahashi T, Ueda R. 1993. MLLT3 gene on 9p22 involved in $\mathrm{t}(9 ; 11)$ leukemia encodes a serine/prolinerich protein homologous to MLLT1 on 19p13. Oncogene 8:3085-3092.

ISCN. 1995. Guidelines for cancer cytogenetics. In: Mitelman F, editor. Basel: S. Karger.

Lochner N, Siegler G, Greil J, Beck J, Fey G, Marschalek R. 1996. Exon/intron structure of the human $A L L-1$ (MLL) gene involved in translocations to chromosomal region $11 \mathrm{q} 23$ and acute leukemias. Br J Haematol 93:966-972.

Martinez-Climent J, Lane N, Rubin C, Morgan E, Johnstone H, Mick R, Murphy S, Vardiman J, Larson R, Le Beau M, Rowley J. 1995. Clinical and prognostic significance of chromosomal abnormalities in childhood acute myeloid leukemia de novo. Leukemia 9:95-101.

Mrozek K, Heinonen K, Lawrence D, Carroll AJ, Koduru PR, Rao KW, Strout MP, Hutchinson RE, Moore JO, Maver RJ, Schiffer CA, Bloomfield CD. 1997. Adult patients with de novo acute myeloid leukemia and $\mathrm{t}(9 ; 11)(\mathrm{p} 22 ; \mathrm{q} 23)$ have a superior outcome to patients with other translocations involving band 11q23: a cancer and leukemia group B study. Blood 90:4532-4538.

Nakamura T, Alder H, Gu Y, Prasad R, Canaani O, Kamada N, Gale
RP, Lange B, Crist WM, Nowell PC. 1993. Genes on chromosomes 4, 9, and 19 involved in 11q23 abnormalities in acute leukemia share sequence homology and/or common motifs. Proc Natl Acad Sci USA 90:4631-4635.

Rowley JD, Reshmi S, Carlson K, Roulston D. 1999. Spectral karyotype analysis of T-cell acute leukemia. Blood 93:2038-2042.

Strissel PL, Strick R, Tomek RJ, Bruce AR, Rowley JD, Zeleznik-Le NJ. 2000. AF9, a common partner gene in MLL translocations of leukemia patients, demonstrates similar DNA structural properties of $M L L$ that could act as recombination "hot spots.” Hum Mol Genet 9:1671-1679.

Super HG, Strissel PL, Sobulo OM, Burian D, Reshmi SC, Roe B, Zeleznik-Le NJ, Diaz MO, Rowley JD. 1997. Identification of complex genomic breakpoint junctions in the $t(9 ; 11)$ MLL-AF 9 fusion gene in acute leukemia. Genes Chromosomes Cancer 20: $185-195$.

Swansbury GJ, Slater R, Bain BJ, Moorman AV, Secker-Walker LM. 1998. Hematological malignancies with $\mathrm{t}(9 ; 11)(\mathrm{p} 21-22 ; \mathrm{q} 23)$ : a laboratory and clinical study of 125 cases-European 11q23 Workshop participants. Leukemia 12:792-800.

Tsuchiya S, Yamabe M, Yamaguchi Y, Kobayashi Y, Konno T, Tada K. 1980. Establishment and characterization of a human acute monocytic leukemia cell line (THP-1). Int J Cancer 26:171-176.

Yamamoto K, Seto M, Iida S, Komatsu H, Kamada N, Kojima S, Kodera Y, Nakazawa S, Saito H, Takahashi T. 1994. A reverse transcriptase-polymerase chain reaction detects heterogeneous chimeric mRNAs in leukemias with $11 \mathrm{q} 23$ abnormalities. Blood $83: 2912-2921$ 